\title{
Resistant Starch
}

National Cancer Institute

\section{Source}

National Cancer Institute. Resistant Starch. NCI Thesaurus. Code C94233.

A form of dietary fiber that resists degradation in the small intestine by gastrointestinal

(GI) enzymes with potential chemopreventive and prebiotic activity. Upon consumption of resistant starch, the fiber is not metabolized or absorbed in the small intestine and enters the colon unaltered. Once in the colon, the starch is fermented by anaerobic colonic bacteria and produces short-chain fatty acids (SCFA), including butyrate, which has antiinflammatory and immunoregulatory activities. In addition, butyrate appears to exert antitumor effects by inhibiting tumor cell proliferation, inducing tumor cell differentiation and apoptosis in colorectal cancer cells. 